NIST Technical Note 1725

\title{
Annex 47 Report 1: Commissioning Overview
}

Chloé Legris

Daniel Choinière

Natascha Milesi Ferretti

http://dx.doi.org/10.6028/NIST.TN.1725

National Institute of Standards and Technology U.S. Department of Commerce 
NIST Technical Note 1725

\section{Annex 47 Report 1: Commissioning Overview}

Chloé Legris

Daniel Choinière

Natural Resources Canada

CanmetENERGY

Energy Technology Centre

Natascha Milesi Ferretti

National Institute of Standards and Technology

Engineering Laboratory

http://dx.doi.org/10.6028/NIST.TN.1725

November 2010

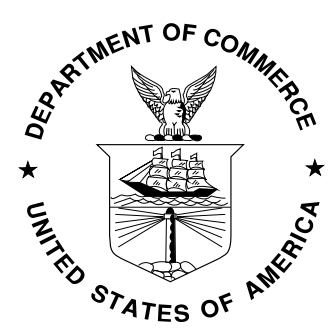

U.S. Department of Commerce Rebecca Blank, Acting Secretary

National Institute of Standards and Technology Patrick D. Gallagher, Under Secretary of Commerce for Standards and Technology and Director 
Certain commercial entities, equipment, or materials may be identified in this document in order to describe an experimental procedure or concept adequately. Such identification is not intended to imply recommendation or endorsement by the National Institute of Standards and Technology, nor is it intended to imply that the entities, materials, or equipment are necessarily the best available for the purpose.

National Institute of Standards and Technology Technical Note 1725 Natl. Inst. Stand. Technol. Tech. Note 1725, 37 pages (November 2010) http://dx.doi.org/10.6028/NIST.TN.1725 CODEN: NTNOEF 


\section{CITATION}

Legris, C. et al. “Annex 47 Report 1: Commissioning Overview”, National Institute of Standards and Technology, Technical Note 1725. November 2010.

This publication was simultaneously published by Natural Resources Canada as Legris, C. et al. “Annex 47 Report 1: Commissioning Overview”, a Report of Cost-Effective Commissioning of Existing and Low Energy Buildings. November 2010.

Copies of this report may be obtained from the Annex 47 web site at: http://www.ieaannex47.org , the NIST website at: http://www.nist.gov, or from the IEA/ECBCS Bookshop at: www.ecbcs.org.

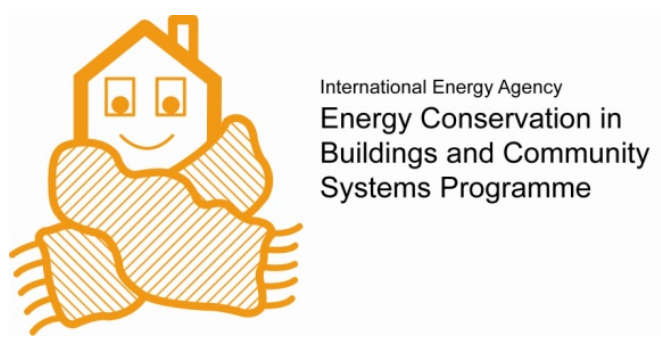




\section{Preface}

\section{International Energy Agency}

The International Energy Agency (IEA) was established in 1974 within the framework of the Organisation for Economic Co-operation and Development (OECD) to implement an international energy programme. A basic aim of the IEA is to foster co-operation among the twenty-eight IEA participating countries and to increase energy security through energy conservation, development of alternative energy sources and energy research, development and demonstration (RD\&D).

\section{Energy Conservation in Buildings and Community Systems}

The IEA co-ordinates research and development in a number of areas related to energy. The mission of one of those areas, the ECBCS - Energy Conservation for Building and Community Systems Programme, is to develop and facilitate the integration of technologies and processes for energy efficiency and conservation into healthy, low emission, and sustainable buildings and communities, through innovation and research.

The research and development strategies of the ECBCS Programme are derived from research drivers, national programmes within IEA countries, and the IEA Future Building Forum Think Tank Workshop, held in March 2007. The R\&D strategies represent a collective input of the Executive Committee members to exploit technological opportunities to save energy in the buildings sector, and to remove technical obstacles to market penetration of new energy conservation technologies. The R\&D strategies apply to residential, commercial, office buildings and community systems, and will impact the building industry in three focus areas of R\&D activities:

- Dissemination

- Decision-making

- Building products and systems

\section{The Executive Committee}

Overall control of the program is maintained by an Executive Committee, which not only monitors existing projects but also identifies new areas where collaborative effort may be 
beneficial. To date the following projects have been initiated by the executive committee on Energy Conservation in Buildings and Community Systems (completed projects are identified by $(*)$ :

Annex 1: $\quad$ Load Energy Determination of Buildings (*)

Annex 2: $\quad$ Ekistics and Advanced Community Energy Systems $(*)$

Annex 3: $\quad$ Energy Conservation in Residential Buildings (*)

Annex 4: $\quad$ Glasgow Commercial Building Monitoring $\left({ }^{*}\right)$

Annex 5: $\quad$ Air Infiltration and Ventilation Centre

Annex 6: $\quad$ Energy Systems and Design of Communities $(*)$

Annex 7: $\quad$ Local Government Energy Planning $(*)$

Annex 8: $\quad$ Inhabitants Behaviour with Regard to Ventilation (*)

Annex 9: $\quad$ Minimum Ventilation Rates $(*)$

Annex 10: $\quad$ Building HVAC System Simulation (*)

Annex 11: $\quad$ Energy Auditing (*)

Annex 12: Windows and Fenestration $\left({ }^{*}\right)$

Annex 13: $\quad$ Energy Management in Hospitals $(*)$

Annex 14: Condensation and Energy $(*)$

Annex 15: $\quad$ Energy Efficiency in Schools $(*)$

Annex 16: $\quad$ BEMS 1- User Interfaces and System Integration (*)

Annex 17: $\quad$ BEMS 2- Evaluation and Emulation Techniques (*)

Annex 18: Demand Controlled Ventilation Systems (*)

Annex 19: $\quad$ Low Slope Roof Systems (*)

Annex 20: $\quad$ Air Flow Patterns within Buildings (*)

Annex 21: $\quad$ Thermal Modelling $(*)$

Annex 22: $\quad$ Energy Efficient Communities (*)

Annex 23: $\quad$ Multi Zone Air Flow Modelling (COMIS) $\left({ }^{*}\right)$

Annex 24: Heat, Air and Moisture Transfer in Envelopes (*)

Annex 25: $\quad$ Real time HVAC Simulation (*)

Annex 26: $\quad$ Energy Efficient Ventilation of Large Enclosures (*)

Annex 27: Evaluation and Demonstration of Domestic Ventilation Systems (*) 
Annex 28: $\quad$ Low Energy Cooling Systems (*)

Annex 29: $\quad$ Daylight in Buildings (*)

Annex 30: $\quad$ Bringing Simulation to Application (*)

Annex 31: Energy-Related Environmental Impact of Buildings $(*)$

Annex 32: Integral Building Envelope Performance Assessment $\left({ }^{*}\right)$

Annex 33: $\quad$ Advanced Local Energy Planning $(*)$

Annex 34: $\quad$ Computer-Aided Evaluation of HVAC System Performance (*)

Annex 35: Design of Energy Efficient Hybrid Ventilation (HYBVENT) $\left({ }^{*}\right)$

Annex 36: $\quad$ Retrofitting of Educational Buildings $(*)$

Annex 37: Low Exergy Systems for Heating and Cooling of Buildings (LowEx) (*)

Annex 38: $\quad$ Solar Sustainable Housing $(*)$

Annex 39: $\quad$ High Performance Insulation Systems (*)

Annex 40: $\quad$ Building Commissioning to Improve Energy Performance $(*)$

Annex 41: Whole Building Heat, Air and Moisture Response (MOIST-ENG) $\left({ }^{*}\right)$

Annex 42: The Simulation of Building-Integrated Fuel Cell and Other Cogeneration Systems (FC+COGEN-SIM) $(*)$

Annex 43: $\quad$ Testing and Validation of Building Energy Simulation Tools (*)

Annex 44: Integrating Environmentally Responsive Elements in Buildings

Annex 45: $\quad$ Energy Efficient Electric Lighting for Buildings $(*)$

Annex 46: Holistic Assessment Tool-kit on Energy Efficient Retrofit Measures for Government Buildings (EnERGo)

Annex 47: Cost-Effective Commissioning for Existing and Low Energy Buildings

Annex 48: Heat Pumping and Reversible Air Conditioning

Annex 49: $\quad$ Low Exergy Systems for High Performance Buildings and Communities

Annex 50: Prefabricated Systems for Low Energy Renovation of Residential Buildings

Annex 51: Energy Efficient Communities

Annex 52: Towards Net Zero Energy Solar Buildings

Annex 53: $\quad$ Total Energy Use in Buildings: Analysis \& Evaluation Methods

Annex 54: $\quad$ Analysis of Micro-Generation \& Related Energy Technologies in Buildings 
Annex 55: Reliability of Energy Efficient Building Retrofitting - Probability Assessment of Performance \& Cost (RAP-RETRO)

Annex 56: $\quad$ Energy and Greenhouse Gas Optimised Building Renovation

Working Group - Energy Efficiency in Educational Buildings (*)

Working Group - Indicators of Energy Efficiency in Cold Climate Buildings (*)

Working Group - Annex 36 Extension: The Energy Concept Adviser (*)

Working Group - Energy Efficient Communities

(*) - Completed

\section{Annex 47}

The objectives of Annex 47 were to enable the effective commissioning of existing and future buildings in order to improve their operating performance. The main objective of this Annex was to advance the state-of-the-art of building commissioning by:

D Extending previously developed methods and tools to address advanced systems and low energy buildings, utilizing design data and the buildings' own systems in commissioning

$>$ Automating the commissioning process to the extent practicable

D Developing methodologies and tools to improve operation of buildings in use, including identifying the best energy saving opportunities in HVAC system renovations

$>$ Quantifying and improving the costs and benefits of commissioning, including the persistence of benefits and the role of automated tools in improving persistence and reducing costs without sacrificing other important commissioning considerations

To accomplish these objectives Annex 47 has conducted research and development in the framework of the following three Subtasks:

\section{- Subtask A: Initial Commissioning of Advanced and Low Energy Building Systems}

This Subtask addressed what can be done for (the design of) future buildings to enable costeffective commissioning. The focus was set on the concept, design, construction, acceptance, and early operation phase of buildings.

- Subtask B: Commissioning and Optimization of Existing Buildings 
This Subtask addressed needs for existing buildings and systems to conduct cost-effective commissioning. The focus here was set on existing buildings where the conditions for commissioning need to be afforded without documentation and limited means for integrated commissioning.

\section{- Subtask C: Commissioning Cost-Benefits and Persistence}

This Subtask addressed how the cost-benefit situation can be represented. Key answers were provided by developing international consensus methods for evaluating commissioning costbenefit and persistence. The methods were implemented in a cost-benefit and persistence database using field data.

Annex 47 was an international joint effort conducted by 50 organizations in 11 countries:

\begin{tabular}{|c|c|}
\hline Belgium & $\begin{array}{ll}\text { - } & \text { KaHo St-Lieven, } \\
\text { - } \quad & \text { Ghent University, } \\
\text { - } & \text { PHP Passive house platform, } \\
\text { - } \quad \text { Kathersité de Liège, } \\
\end{array}$ \\
\hline Canada & $\begin{array}{l}\text { - Natural Resources Canada (CETC-Varennes), } \\
\text { - Public Works and Governmental Services Canada, } \\
\text { - } \quad \text { Palais de Congres de Montreal, } \\
\quad \text { Hydro Quebec, }\end{array}$ \\
\hline Czech Republic & - $\quad$ Czech Technical University \\
\hline Finland & $\begin{array}{l}\text { VTT Technical Research Centre of Finland, } \\
\text { - Helsinki University of Technology }\end{array}$ \\
\hline Germany & $\begin{array}{ll}\text { - } & \text { Ebert-Baumann Engineers, } \\
\text { - } \quad \text { Institute of Building Services and Energy Design, } \\
\quad \text { Fraunhofer Institute for Solar Energy Systems ISE }\end{array}$ \\
\hline Hong Kong/China & - $\quad$ Hong Kong Polytechnic University \\
\hline Hungary & - University of Pécs \\
\hline Japan & 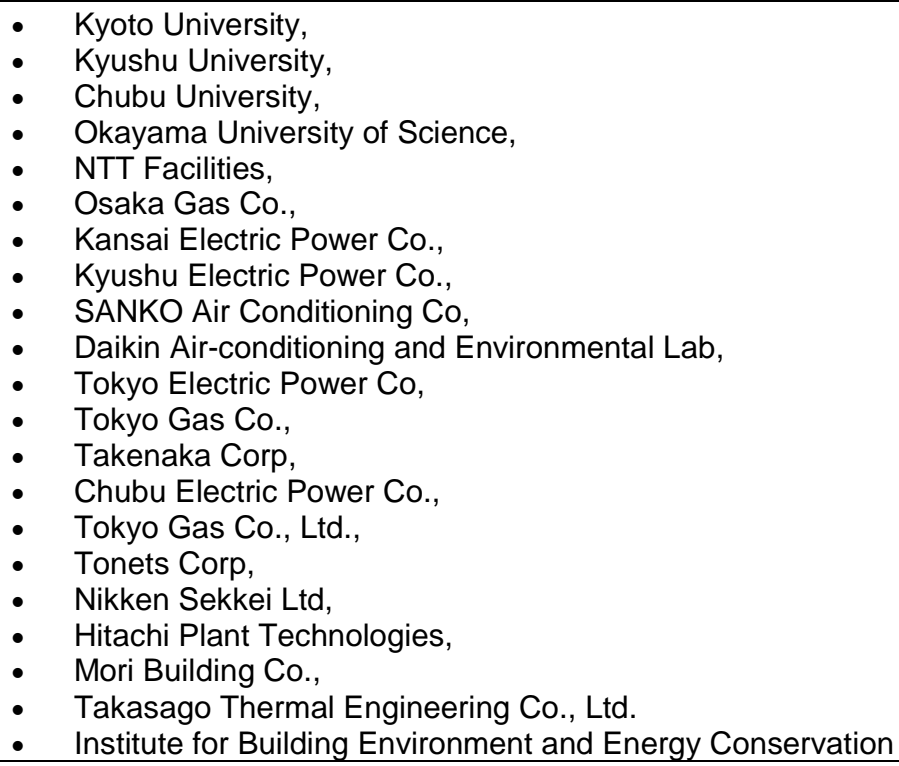 \\
\hline Netherlands & $\begin{array}{l}\text { TNO Environment and Geosciences, } \\
\text { - University of Delft }\end{array}$ \\
\hline Norway & $\begin{array}{ll}\text { - } & \text { Norwegian University of Science and Technology, } \\
\text { - SINTEF }\end{array}$ \\
\hline
\end{tabular}




\begin{tabular}{|c|c|}
\hline USA & $\begin{array}{ll}\text { - } & \text { National Institute of Standards and Technology, } \\
\text { - } & \text { Texas A\&M University, } \\
\text { - } & \text { Portland Energy Conservation Inc., } \\
\text { - } & \text { Carnegie Mellon University, } \\
\text { - } & \text { Johnson Controls, } \\
\text { - } & \text { Siemens, } \\
\text { - } & \text { Lawrence Berkeley National Laboratory }\end{array}$ \\
\hline
\end{tabular}




\section{FOREWORD}

This report summarizes part of the work of IEA-ECBCS Annex 47 Cost-Effective Commissioning of Existing and Low Energy Buildings. It is based on the research findings from the participating countries. The publication is an official Annex report.

Report 1, 'Commissioning Overview' can be considered as an introduction to the commissioning process.

Report 2, 'Commissioning Tools for Existing and Low Energy Buildings' provides general information on the use of tools to enhance the commissioning of low energy and existing buildings, summarizes the specifications for tools developed in the Annex and presents building case studies.

Report 3, 'Commissioning Cost Benefit and Persistence' presents a collection of data that would be of use in promoting commissioning of new and existing buildings and defines methods for determining costs, benefits, and persistence of commissioning, The report also highlights national differences in the definition of commissioning.

Report 4, Flowcharts and Data Models for Initial Commissioning of Advanced and Low Energy Building Systems' provides a state of the art description of the use of flow charts and data models in the practice and research of initial commissioning of advanced and low energy building systems.

In many countries, commissioning is still an emerging activity and in all countries, advances are needed for greater formalization and standardization. We hope that this report will be useful to promote best practices, to advance its development and to serve as the basis of further research in this growing field.

Natascha Milesi Ferretti and Daniel Choinière

Annex 47 Co-Operating Agents 


\section{ACKNOWLEDGEMENT}

The material presented in this publication has been collected and developed within an Annex of the IEA Implementing Agreement Energy Conservation in Buildings and Community systems, Annex 47, “Cost-Effective Commissioning of Existing and Low Energy Buildings”.

This report, together with the three companions Annex reports are the result of an international joint effort conducted in 10 countries. All those who have contributed to the project are gratefully acknowledged.

On behalf of all participants, the members of the Executive Committee of IEA Energy Conservation in Building and Community Systems Implementing Agreement as well as the funding bodies are also gratefully acknowledged.

A list of participating countries, institutes, and people as well as funding organizations can be found at the end of this report. 


\section{TABLE OF CONTENT}

1 BACKGROUND OF SUSTAINABLE MAINTENANCE, CONTINUOUS BUILDING

OPTIMIZATION OR COMMISSIONING ............................................................................................................14

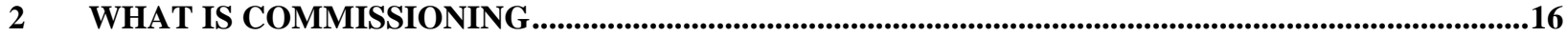

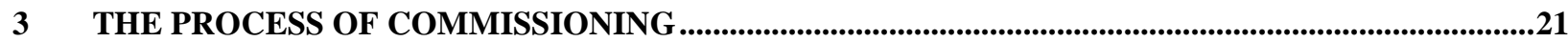

4 COSTS OF COMMISSIONING, RECOMMISSIONING AND ONGOING COMMISSONING............22

$5 \quad$ RISKS FOR NOT IMPLEMENTING A COMMISSIONING PROCESS....................................................25

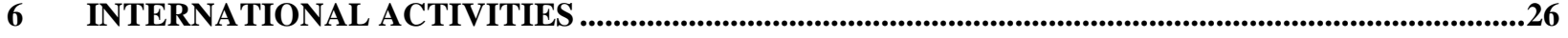

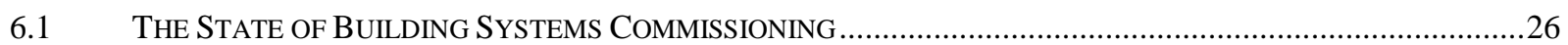

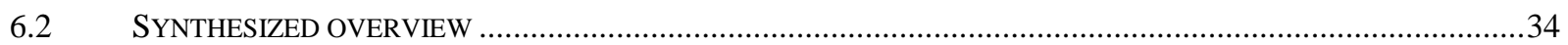

$7 \quad$ REFERENCE AND COMMISSIONING GUIDES.......................................................................................36

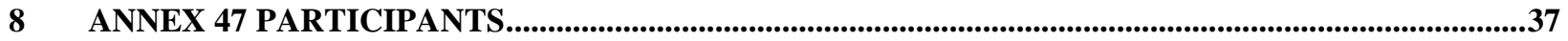




\section{$1 \quad$ Background of Sustainable Maintenance, Continuous Building Optimization or Commissioning}

Approximately one-third of the global energy use is attributed to buildings and, despite improvements in the thermal performance of buildings, is inefficiently used (IEA 2008). This information, coupled with an increased understanding of the environmental impact of the building sector and concerns for energy availability, is highlighting the important role of energy efficient technologies and effective delivery processes.

Most IEA countries have their own established procedures for building design, construction and operations, however, current approaches are frequently inadequate for ensuring that buildings perform as intended. A major factor is that the buildings industry is strongly driven by first cost; therefore, investment decisions, when made without considering payback over the building lifecycle, present a barrier to improving the building stock and environmental stewardship. Furthermore, the complex and often opaque definitions of roles and responsibilities for members of the building industry lead to inefficiencies and information gaps in the lifecycle, even for conventional building systems. As non-conventional systems are introduced, a lack of familiarity by the designers, installers, or end-users can lead to the misapplication of technologies and result in poor performance. This risk increases the need for independent quality assurance.

When a building is commissioned it goes through a systematic, quality assurance process. This process, which spans the design, construction, and operation of the building and its systems, is a valuable mechanism for quality building delivery. The process is aligned with industry bestpractices, and involves commissioning agents, building owners, architects, engineers, and building operators, among others. It includes activities such as developing documents such as the Owners Project Requirements, planning for and carrying out verification checklists, functional tests, developing a complete Systems Manual, and training requirements, and performing seasonal/deferred testing. Commissioning ensures that the building meets the owner's needs and operates efficiently, and lays the groundwork for training the operations and maintenance staff to maintain systems over the life of the building. The overarching benefits include reduced lifecycle costs, improved occupant comfort and productivity, and cost-effective maintenance.

The goal of IEA - ECBCS Annex 47 was to enable the cost-effective commissioning of existing and future buildings in order to improve their operating performance. The commissioning techniques developed through this Annex are intended to help transition the industry from the intuitive approach that is currently employed in the operation of buildings to more systematic operation that focuses on achieving significant energy savings. The Annex also serves as a means to exchange information on commissioning practices in different countries and disseminate relevant information to national practitioners.

Key outputs of IEA - ECBCS Annex 47 include:

- Methods and tools for commissioning advanced systems and low energy buildings;

- Methods and tools for field application; 
- Information on the costs and benefits that can be used to promote the wider use of commissioning. 


\section{$2 \quad$ What is Commissioning}

IEA Annex 40 defined Commissioning is a "quality-oriented process for achieving, verifying and documenting whether the performance of a building's systems and assemblies meet defined objectives and criteria.” This internationally established definition is quite close to the definition used by ASHRAE (the American Society of Heating, Refrigerating, and Air Conditioning Engineers), that stipulates that Commissioning is " the process of ensuring that systems are designed, installed, functionally tested and capable of being operated and maintained to perform in conformity with the design intent.”

In practice one can differentiate 4 types of commissioning which are describe below and represented on the following figure:

o Initial commissioning begins during design and continues through construction and occupancy. It helps ensure that the performance of the new building or major retrofit meets owner's expectations.

o Retrocommissioning is the first time commissioning is implemented in an existing building in which a documented commissioning process was not previously implemented.

o Recommissioning is another type of commissioning that occurs when a building that has already been commissioned undergoes another commissioning process. Most buildings experience degradation in performance that, if left untreated, will reduce occupant productivity and energy efficiency, often well before comfort complaints trigger a response. It's implemented after I-Cx or Retro-Cx when the owner hopes to verify, improve and document the performance of building systems.

o Lifetime commissioning or ongoing commissioning is a commissioning process conducted continually for the purposes of maintaining, improving and optimizing the performance of building systems initial or re/retro commissioning.

\begin{tabular}{|c|c|c|c|c|c|c|c|}
\hline \multicolumn{9}{|c|}{ Production } & Operations \& Maintenance \\
\hline Pre-Design & \multicolumn{2}{|c|}{ Design } & Elaboration & \multicolumn{2}{c|}{ Construction } & \multicolumn{2}{c|}{ Occupancy \& Operation } \\
\hline Program & Planning & $\begin{array}{c}\text { Preliminary } \\
\text { Design }\end{array}$ & $\begin{array}{c}\text { Working } \\
\text { Design }\end{array}$ & Elaboration & Construction & Acceptance & \multicolumn{2}{c|}{$\begin{array}{c}\text { Post- } \\
\text { Acceptance }\end{array}$} & $\begin{array}{c}\text { Ordinary } \\
\text { Operation }\end{array}$ \\
\hline & \multicolumn{3}{|c|}{ Initial Commissioning } & $\begin{array}{c}\text { Ongoing } \\
\text { Commissioning }\end{array}$ \\
\hline
\end{tabular}

As shown on the figure above, commissioning ideally starts as soon as a new facility is conceptualized, and it continues until the building is occupied. Through this process, expectations for the performance of the building systems are established and procedures are put in place to determine whether those expectations have been met. 
Unfortunately, commissioning is too often viewed as a task performed after a building is constructed and before it is handed over to the building owner to check operational performance. We clearly favoured a broader view that enables gaps bridging between 4 different visions:

\section{- The expectations of the building owner}

4 The process allows the building owner to clarify its expectations and ensure the designer to obtain all owner's project requirements (OPR), so that owner and designer understand one another and are in agreement.

\section{- The project of the designer}

The process helps in translating the designer's project into appropriate specifications which can be understood, realized and verified by the contractor.

\section{- The assembled system of the contractor}

The process ensures that functional performance testing procedures are applied, which will enable the contractor, the building owner and the designer to verify that the system is clearly operating as expected.

\section{- The running system of the operator}

The process include the production of system manuals which will enable the operator to take best profit of the ideas of the designers and of the system realized by the contractor to fulfill owner requirements.

The process must be continuously integrated by producing, at regular intervals, a report which will enable the operator and the building owner to check that the operation continues to fulfill the requirements.

This broad view could appear to many users as a dream which could be realised in a few projects but which is too far from their day to day practice to be practicable to their projects. In practice one applies often only one part of the full process. Next section will introduce most benefits that might help convince that a complete and fully integrated commissioning at the true beginning of a project is worthwhile.

\section{WHAT BUILDING COMMISSIONING IS NOT}

Commissioning is not...:

- an additional phase of a project;

- an isolated testing event;

- a TAB (testing, adjusting, balancing);

- an equipment start-up

Commissioning will likely involve $\mathrm{TAB}$, equipment start-up, and testing of various types, but these are just a part of the larger whole of the commissioning process as it occurs throughout all phases of a project. 
Commissioning benefits are far-reaching. Each of the participants in the design and construction process will benefit from commissioning, and so will the building's owner, staff and future occupants. Through this process, a necessary improved coordination between design, construction and occupancy will occur and permit to reach financial, comfort and performance benefits, as described here:

\section{- Reduced life-cycle costs}

In the long term, the projected life-cycle costs of buildings and facilities will be reduced as a result of the integrated efforts of the designer and the building operators to meet commissioning requirements. It will contribute to reduce construction costs while ensuring a more efficient use of energy over the years.

\section{- Cost effective maintenance}

Involvement of O\&M staff in commissioning, plus the training and documentation provided, is the basis for more effective operation, maintenance and management throughout the life of the facility.

\section{- Occupant satisfaction}

The primary and immediate beneficiaries of a properly designed, constructed and commissioned facility are the occupants. They will enjoy the advantages of living or working in an improved indoor environmental quality that's comfortable and safe and in surroundings that meet their everyday needs. Further benefits will accrue to the Owner/Investor as a result of having satisfied tenants in a quality building that complies with the requirements of the investment plan. Also, when building quality is translated into higher productivity and reduced absenteeism of the occupants, the overall savings become even more significant.

\section{- Quality assurance}

The Owner/Investor is assured that a quality facility and a "surprise-free" product/environment have been provided. There will be fewer system deficiencies at building turnover. This will be achieved by ensuring that:

- the Contract Documents include all commissioning specifications,

- the requirements of these specifications will be met

- fully documented tests and inspections will prevent minor errors from developing into serious operational flaws.

\section{- System performance verification}

Commissioning extends into Operation phase, in order to verify performance under a full 
range of operating conditions. This practice aims to provide a "no-surprises" operation cycle for both Owners and operation and maintenance (O\&M) staff. A thorough process will help to avoid unforeseen or hidden O\&M expenses later.

\section{- System documentation}

Provision of accurate and useful historical records is assured. Such records provide important data for O\&M efforts as well as for future renovations, upgrades or repairs. Technical reports and other commissioning documents serve as benchmarks for future system testing, re-commissioning and for maintenance or renovation activities.

\section{- Knowledge transfer}

- Systematic development of commissioning documentation facilitates knowledge transfer from one phase of delivery to the next and from the delivery process to the ensuing ongoing operation of the facility.

- Feedback through project management and report mechanisms can provide benefits to other projects by reporting on experience gained through the Validation and Acceptance Process.

\section{- Protection of heritage character}

The training and documentation provided and involvement of O\&M staff in commissioning is the basis for informed maintenance that is sensitive to the needs of heritage materials and assemblies.

\section{- LEED and BREEAM certification}

Commissioning is a requirements of various programs such as Leadership in Environmental and Energy Design (LEED), Building Research Establishment Environmental Assessment Method (BREEAM), Quality Guideline C2000 and enable the project to obtain the appropriate certification.

As seen above, many benefits from commissioning are not energy related. These have been studied over 36 recommissioning projects by the Lawrence Berkeley National Laboratory. As summarized on the next graph, we can see that one-third of the projects have observed an increase durability of their equipment. When the financial values of these non-energy impacts were quantified, the savings were estimated to be between $\$ 1$ and $\$ 4.75$ per year $/ \mathrm{m}^{2}$. 


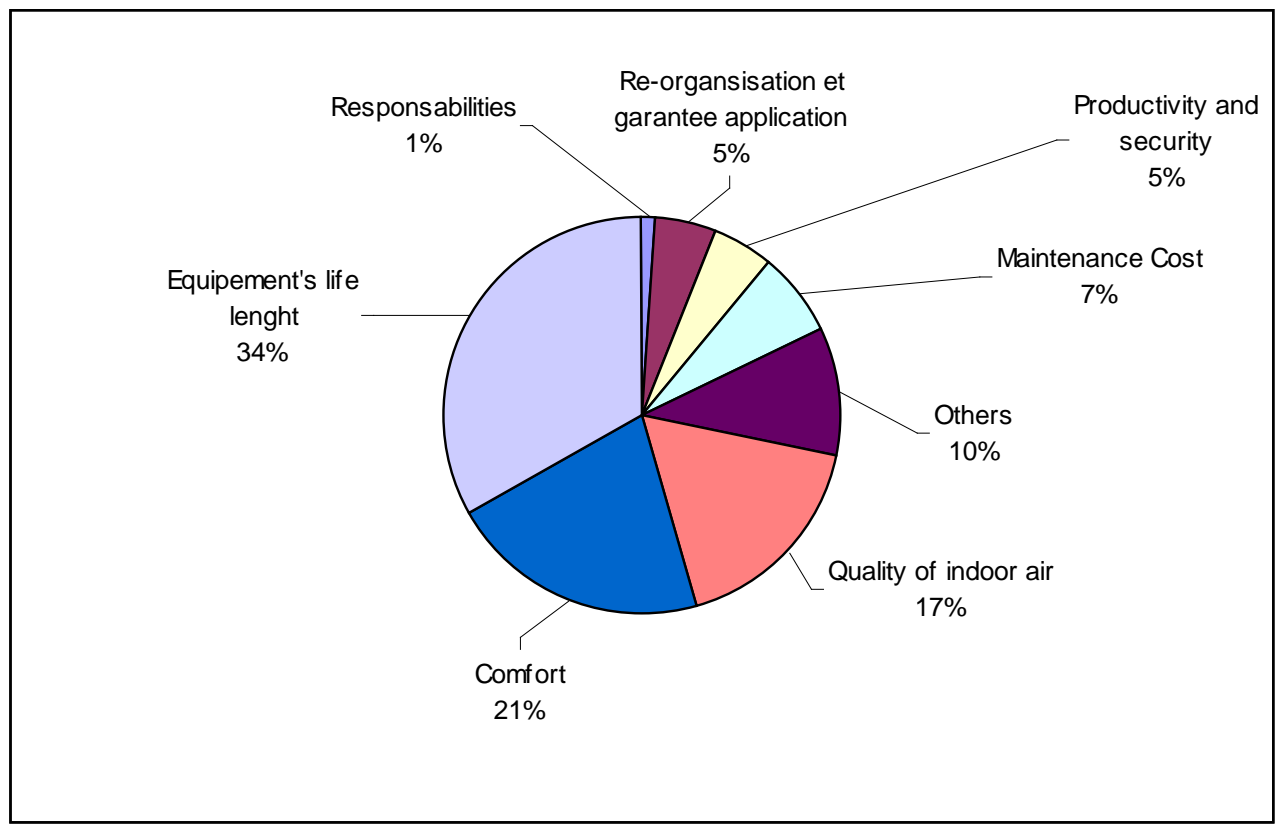

Source: Lawrence

Berkeley National

Laboratory, «The

Cost Effectiveness of

Commercial-Buildings

Commissioning 》,

December 2004. 


\section{The Process of Commissioning}

A commissioning process is composed of 4 distinct phases: pre-design, design, construction and occupancy/operation. The figure found on next page describe briefly each of these phase.

Different guides written by different organizations worldwide are available and explain in details those different phases. As an example, the IEA Annex 40 developed five Standard Commissioning Plans. These plans are based on the building size and HVAC System complexity. They include typical lists of tasks with a description of the content of each task. They can be used as a basis to define customized Commissioning Plans adapted to a given project.

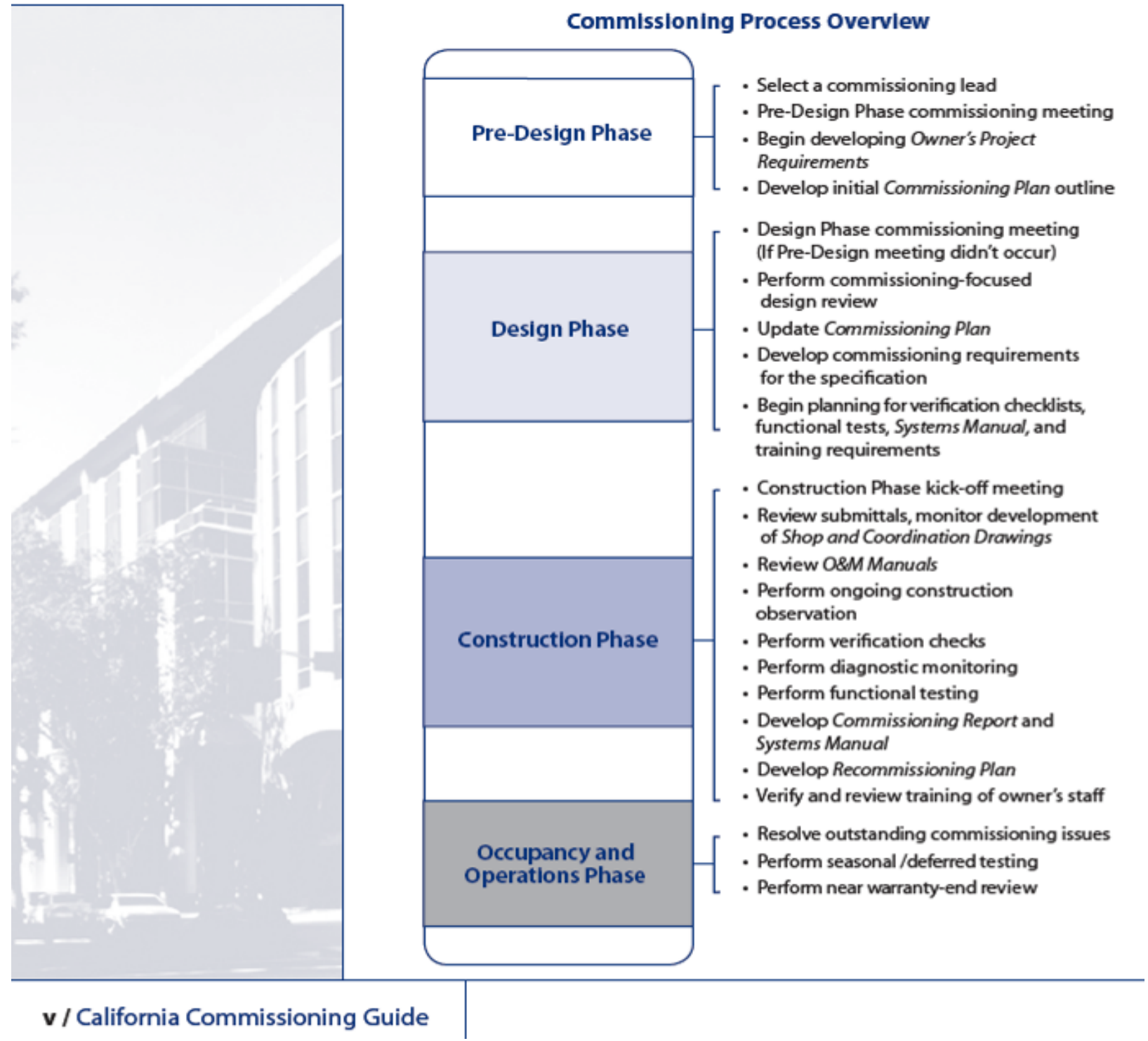




\section{$4 \quad$ Costs of Commissioning, Recommissioning and Ongoing Commissoning}

Costs of commissioning, recommissioning and ongoing commissioning will obviously differ form each other, but regardless of the type of commissioning being implemented, the cost for each project depends on:

- the scope of the process;

- the size of the project;

- $\quad$ the complexity of the system;

- the age and condition of existing equipments;

- the staff level of knowledge;

- the presence of adequate documentation.

Therefore, commissioning costs are difficult to estimate. There is no standard convention for determining which costs are included in the total cost of commissioning. For instance, a research laboratory with stringent air quality and ventilation requirements will necessitate more extensive and costly commissioning than a general-purpose warehouse.

The commissioning lead's fee is the most obvious cost, but sometimes the costs to other team members who participate in the commissioning process, and the cost of correcting problems identified by commissioning are also counted. Early involvement of the commissioning manager to help prepare the commissioning plan and budget will be instrumental in achieving control over the costs of commissioning.

Because it's hard to define precisely, the cost of commissioning is most commonly and accurately presented as a range of potential costs rather than a specific dollar amount. No matter how it is defined, however, the cost of commissioning accounts for only a very small part of the overall construction budget, and an even smaller part of the building's lifecycle costs.

\section{Commissioning Costs - Starting the process from the beginning}

Many commissioning activities and supporting documentation are already being performed as normal standard practice and do not constitute extra costs. Other commissioning activities, traditionally not provided by the design and construction industry, represent additional responsibilities for the project manager, designer and contractor.

In balance, there will undoubtedly be some additional initial costs to carrying out commissioning procedures. These will depend upon the degree of risk of non-compliance with the occupant's requirements or the life-cycle quality and cost plan the Owner is prepared to undertake. Here's a figure that shows commissioning costs as reported in a study of 69 commissioning projects. 
Typical Commissioning Costs

\begin{tabular}{|l|c|}
\hline \multicolumn{1}{|c|}{ Description } & Value or Range \\
\hline Total Cx Cost & $\$ 4.90-\$ 16.60 / \mathrm{m}^{2}$ \\
\hline Cx Provider Fee as \% of Total Commissioning Cost & $74 \%-86 \%$ \\
\hline Provider Fee as \% of Total Construction Cost & $0.3 \%-1.1 \%$ \\
\hline Design Review & $18 \%$ \\
\hline Construction Observation & $14 \%$ \\
\hline Acceptance Testing & $64 \%$ \\
\hline Warranty & $4 \%$ \\
\hline
\end{tabular}

It has often been observed that O\&M costs during the first year of operation are $50 \%$ to $150 \%$ higher than during following years. Experience, however, also indicates that the cost of commissioning is more than recovered through reduced O\&M costs during this initial year of operation.

\section{Recommissioning Costs - Starting the process a few years after building start-up}

While costs vary depending on the complexity of the systems and project goals, recent studies show typical recommissioning project costs to be about $\$ 2.90 / \mathrm{m}^{2}$. A Lawrence Berkeley National Laboratory's study of 100 existing buildings (varying in type and size) found that recommissioning provider fees ranged from $35 \%$ to $71 \%$ of the total recommissioning costs. As shown in figure below, the largest percentage of costs for a project was for the investigation and planning phase activities (69\%), followed by the actual implementation of measures (27\%).

\section{Typical Recommissioning Costs}

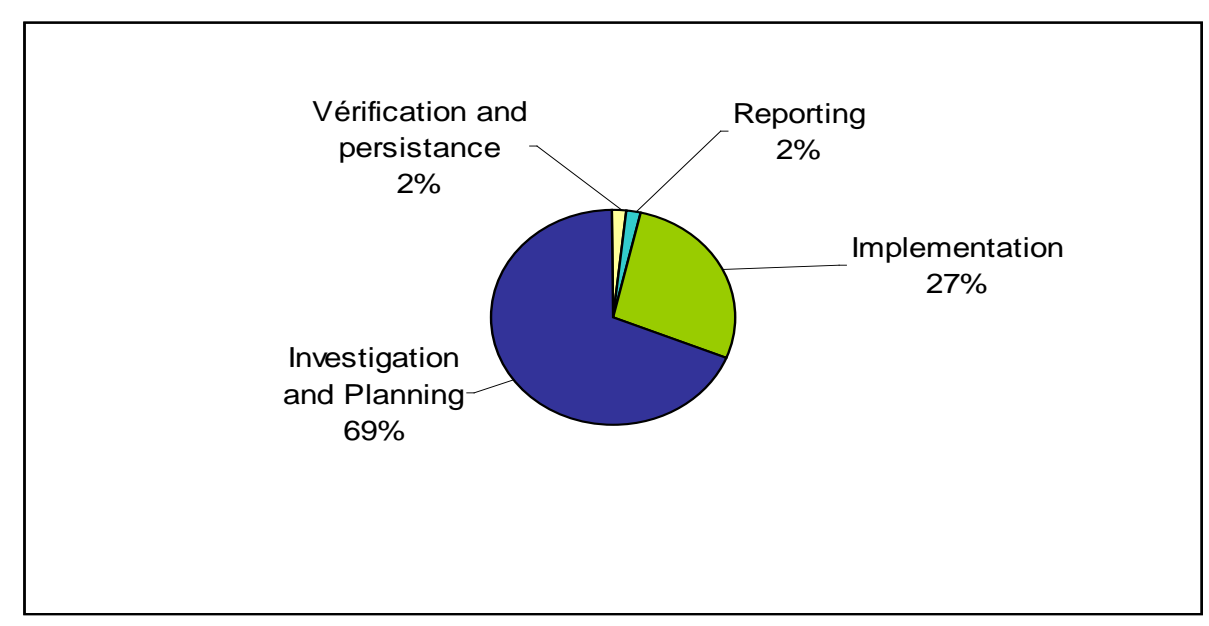

Source: Lawrence Berkeley National Laboratory, "The Cost Effectiveness of Commercial-Buildings Commissioning," December 2004. 


\section{Variables of commissioning costs}

Experience to date indicates that full commissioning adds between $1 \%$ and $40 \%$ to the mechanical and electrical construction cost of projects. These extra costs can be attributed to the provision of services not usually included in design and construction projects, such as:

- Preparation of a commissioning plan;

- Increased coordination between the designer and property management staff;

- Available documentation and staff knowledge (for RCx);

- Production of more extensive systems documentation;

- Enhanced O\&M documentation and training;

- Increased reviews (commissioning plan, commissioning specifications, design, building management manual, ...);

- Increased inspections and testing during construction;

- Temporary instrumentation requirements;

- Performance verification testing;

- Planning staff training;

- Prolongation of the Warranty Period.

Finally, it's important to note that when the monetized value of commissioning's benefits are taken into account, the cost of commissioning is often offset by more than $50 \%$. One of the most significant factors is the ability to reduce a building's net life-cycle costs and its potential to reduce first costs, when commissioning begins early in the design phase of the project. 


\section{$5 \quad$ Risks for Not Implementing a Commissioning Process}

Beyond the direct first-cost aspects of commissioning process, there're other risks and costs associated for not having an appropriate commissioning process. Among these risks, the majors ones are:

\section{Discomfort}

Comfort problems affect every building owner - both those who occupy their facilities and those who lease them.

\section{Reduced Productivity}

An uncomfortable building makes everyone less productive. Occupants spend more time complaining and often take more sick days. Building staff spend more time responding to comfort complaints and have less time to attend to their regular maintenance tasks.

\section{Tenant Retention}

A chronically unhealthy building can cause owners to lose tenants and money. When tenants leave, rent revenues and leasing commissions are lost. In addition, word of uncomfortable building conditions is likely to spread among business peers, increasing vacancy periods.

\section{Building's asset value}

Building owners may suffer from lower appraised building values if the property is not properly appraised for its operating performance. Equipment that is not well-maintained and operates inefficiently decreases the asset value of the property. The U.S. Environmental Protection Agency (US-EPA) has estimated that every dollar invested in energy upgrades yields $\$ 2$ to $\$ 3$ in increased asset value of a building.

\section{Increased Liability}

Owners are increasingly on the receiving end of lawsuits over poor indoor air quality in their buildings. They result in high costs to the owner, inconvenience to tenants, and wasted time on everyone's part. 


\section{$6 \quad$ International Activities}

The global need for improved building performance has led to numerous international collaborations. Because technological and policy developments occur at different rates and in different regions, there is an opportunity for mutual benefit and rapid advancement through the exchange of information. Commissioning research projects under the International Energy Agency's (IEA) Energy Conservation in Buildings and Community Systems (ECBCS) program, Annex 40 (2000-2005) and Annex 47 (2005-2009), provide a forum for the exchange of knowledge and experience among participating countries. Common definitions of the commissioning process were established in Annex 40 (Visier et al. 2005) and the research initiated under each of these projects has become the basis for the development of national guidelines.

\subsection{The State of Building Systems Commissioning}

Regional partnerships and international collaborations to promote the commissioning process have accelerated awareness and adoption. The following sections on the Asia Pacific, Europe, and North America regions provide an overview of the state of building systems commissioning. Each national assessment aims to present the national drivers, leading efforts and an indication of their success (if known). Fifteen countries are represented in this review.

\section{Asia Pacific}

In the Asia Pacific region, the construction industry is experiencing unparalleled growth. China alone reports the annual construction of two billion square meters of floor space, (Qiu, 2008). The environmental impact of this growth has global repercussions. It is therefore critical that the building industry adopt building commissioning as a standard practice to improve the quality and efficiency of design, construction, and operations.

Asia Pacific countries are leveraging national energy laws, institutional mandates, and non-profit organizations to foster development of building systems commissioning. For several countries in the region, recent exposure through international symposia and conferences sparked interest that has developed into national research projects. This exchange of information is particularly useful for countries that have natural synergies, such as climate, that facilitate transfer of technologies or guidelines. Through these cooperative exchanges, countries are able to leapfrog technologies and accelerate adoption.

Australia: Indoor environmental quality assessments, rising energy costs, and a greater understanding of the link between comfort and productivity are driving the demand for improved energy efficiency of buildings in Australia. At present, most of the commissioning projects are associated with major contracts and do not address smaller projects. Furthermore, the fully integrated approaches to project commissioning, promoted by the Chartered Institution of Building Services Engineers (CIBSE) and American Society of Heating, Refrigerating and Air- 
conditioning Engineers (ASHRAE) commissioning guidelines, are not well understood by the commercial sector, and this educational need is yet to be addressed (EcoLibrium 2006).

Awareness of the importance of the commissioning process is increasing, largely due to the market influence of voluntary, performance-based rating schemes such as the National Australian Built Environment Rating System and the Green Building Council's Green Star program. Through this mechanism, several large commercial real estate owners and governmental agencies have made commitments to achieve a certain rating in their building stock. The implementation and promotion of these rating schemes have the potential to trigger the demand for energy audits and commissioning in the existing building stock. Deakin University is developing rapid reporting techniques to facilitate building performance improvement in the commissioning process (Nakahara et al. 2007).

China: Mainland China has seen several construction booms. In the 1980's the rapid growth of residential construction prompted the Ministry of Construction to develop energyefficient building codes. These codes did not include commissioning and quality, in general, was considered poor. In the 1990s, testing and commissioning concepts diffused into the Chinese buildings industry as part of the western management techniques from numerous overseas, joint venture construction projects (Chow et al. 2006). International partnerships now also extend to academic research. Chinese universities, including Tsinghua University, are conducting research on building optimization, building commissioning and other related work. In 2008, China's Ministry for Construction released acceptance codes for building services equipment and building systems, though no information could be obtained regarding the administration and enforcement of these requirements.

Hong Kong was one of the first adopters and developers of the building commissioning process due to early exposure to the United Kingdom's commissioning model. As early as 1990, the Hong Kong Government published twelve booklets based on the CIBSE Commissioning Codes. The documents were developed into commissioning specifications released in 2002 and are intended to be incorporated into government building project contracts (Chow et al. 2006). Furthermore, in 2004, Hong Kong introduced a new voluntary scheme, termed the Consolidated Environmental Performance Assessment Scheme (CEPAS), to promote the design of environmentally-friendly buildings. CEPAS incorporates building commissioning as a major element for performance assessment.

The Hong Kong Building Commissioning Centre (HKBCxC) was established in December 2004 as a non-profit organization whose mission is to promote the establishment of a standardized approach to building commissioning in Hong Kong. The HKBCxC organizes programs for continuing professional development, certification services and publishes guidebooks on the management of building commissioning, field measurements, and system tuning. In the "Practical Guide to Building Commissioning Management", Chow et al (2006) report that independent contracts for commissioning and retro-commissioning are soaring in Hong Kong.

Japan: In 2006, building energy performance reporting became mandatory under the Energy Conservation Law. The reports are based on simple performance tests of the components and systems that have the largest impact on the energy consumption of heating, ventilation, and air- 
conditioning systems. In practice, there is significant variation in the implementation approach because no standard test procedures are specified and it is unclear whether relevant problems could be investigated adequately through the data contained in the reports. Hence, aspects of the commissioning process are drawing more attention in Japan's building sector. In existing buildings, various approaches for retro-commissioning are commonly implemented, but initial commissioning for new construction is not common.

In 2005 the Society of Heating, Air-Conditioning and Sanitary Engineers of Japan (SHASE) technical committee on commissioning issued a guideline on the building services commissioning process. The Building Services Commissioning Association (BSCA), a nonprofit organization launched in 2004, provides seminars about commissioning technologies in major cities and has undertaken cooperative activities with Asian countries such as China (including Hong Kong), Taiwan, and Korea. It also continues to compile commissioning documentation and tools through actual commissioning projects and research. BSCA's strategy is to establish a certification program for commissioning engineers, including the Commissioning Authority, and to educate the construction industry and related government sectors.

Energy policy is playing an important role. The Ministry of Economy, Trade and Industries is interested in a new business model, based on building commissioning, to enhance energy efficiency of new and existing buildings and The Ministry of Land, Infrastructure and Transportation is promoting use of lifecycle energy management with a newly developed simulation tool. Market demand for commissioning is believed to be strong but mandates, based on energy and environmental policy, are needed for building owners to apply building commissioning to new construction.

Taiwan: In Taiwan, building commissioning for new construction is considered established practice. The Taiwanese government has issued a mandate requiring that all public projects with a budget over 15 million U.S. dollars acquire the Green Building Label before a construction permit can be granted. Testing, adjusting and balancing (TAB), commissioning, and the use of a building energy management system (BEMS) are prerequisites. However, the process implemented in Taiwan does not represent the full range of actions from design to operations. The commissioning role in Taiwan for existing buildings is typically similar to that served by energy service companies in Japan and the USA. Taiwan is involved in international activities to expand national practices as deemed necessary. For example, a review of the Green Building Label (similar to Leadership in Energy and Environmental Design (LEED) for new construction in the USA and CASBEE in Japan) suggested that a commissioning plan be added.

A national-scale project was launched in 2003, by the Architecture and Building Research Institute, Ministry of the Interior, to renovate all the central heating, ventilation, and airconditioning (HVAC) systems in governmental buildings for energy conservation. The renovation process includes system diagnostics, remedial strategies, establishing engineering jobs, contracting, TAB, commissioning, and system performance validation through the BEMS. To date, 22 million USD have been spent with an overall energy-savings of $22 \%$ and an average payback of five years. The success has since led to a series of demonstration projects for civil and governmental buildings. In 2008, Taiwan will launch another five-year program where the energy savings effort will be enhanced with greater system fine-tuning and commissioning as a 
means to support the Kyoto Protocol and global $\mathrm{CO}_{2}$ emission reduction efforts.

Korea: The Korean Institute for Energy Research (KIER) is working to promote the commissioning process through energy conservation and quality assurance measures for new construction. Commissioning projects have been carried out by KIER as part of their research work, and have also been implemented in several buildings financed by foreigners. However, there is no recognized national standard and the Korean government has no intention to mandate the commissioning process.

Europe: The countries of the European region present significant differences in their building delivery processes as well as their emphasis on energy efficiency and measures for quality assurance. For most, with the exception of the UK, the commissioning process is quite new. However, the European Commission established the European Performance of Buildings Directive, EPBD (EC 2002), to promote the improvement of energy efficiency and building performance. Four requirements to be implemented by the Member States are to: 1) develop a framework for a methodology to calculate the integrated performance of buildings, 2) set minimum standards in new and existing buildings, 3) certify the energy performance of buildings, and 4) inspect and assess heating and cooling installations.

According to reports from the member states, the EPBD poses significant challenges in terms of its practical implementation, including difficulties associated with the transfer of requirements into existing building practices under a range of climates. However, because the commissioning process is well aligned with the goals of the EPBD, several national research programs are introducing commissioning tools as a means to address the requirements of the directive. In many countries, commissioning tasks are focused on the building handover, or performed as part of the facilities management. However, for commissioning to have a real impact on savings, the review must begin at the pre-design phase, where changes are easier and more cost-effective to make. It is anticipated that the increased attention to energy efficiency in buildings will lead to greater application and consistency of commissioning through the building lifecycle.

Belgium: Commissioning research has been underway in Belgium for several years, and mainstream awareness of the importance of commissioning of low-energy buildings has increased due to the implementation of the EPBD and the introduction of the passive house concept for very low energy building. Energy performance laws, which set requirements for the energy performance and indoor climate for most buildings requiring a building permit, exist in the Flemish Region and are under development in the Brussels and Walloon regions.

Czech Republic: Building commissioning is a new concept in the Czech Republic. Only some aspects of building commissioning are implemented as a part of the facility management and energy auditing processes that are related to EPBD implementation. Under the IEA Annex 47 project, researchers have developed tools that support additional aspects of the broader commissioning process, including new control system energy services. 
Finland: Historically, individual contractors and builders in Finland have managed commissioning-related activities as part of their quality assurance measures. More recently, emphasis has been placed on the development and implementation of "energy auditing" procedures. In 2002, a Finnish national research program called CUBE was launched to improve the performance of building services. This program includes a national R\&D project to develop Finnish procedures for building commissioning, focusing on the indoor air quality and energy efficiency of buildings. The Finnish term and concept of "toimivuuden varmistaminen (ToVa)," an adaptation of building systems commissioning, is being promoted. Practical testing and further development of the guidebook and tools are underway. Methods and tools to support the commissioning of buildings and their subsystems throughout the phases of the building life-cycle are being developed.

France: The commissioning process is just beginning to take hold in France and a national guideline on commissioning is under development. In practice, commissioning is implemented in the operations phase, though there is greater interest from large building owners for more complete commissioning plans as a result of ongoing national research and new requirements under the EPBD. Current research is focused on automating the commissioning process to improve performance, pushing for early implementation of the commissioning process from design through certification, and developing tools and procedures for specific building applications (e.g., schools).

Germany: Commissioning for new construction is not established or even required as a third party service in Germany. German law (HOAI) dictates that architects and design engineers perform the following tasks within the construction administration and construction supervision:

supervising acceptance and performance tests and statement of deficiencies; collecting/compiling and delivering as-built documentation, operating manuals, and acceptance protocols; and

supervising the rectification of deficiencies that fall under the two-year contractor's warranty period or the five-year design team warranty period from date of acceptance.

This approach, initiated in 1976, presents a model for internal commissioning during the construction phase and, in conjunction with energy conservation laws, has resulted in higher performing buildings. Efforts to implement the full commissioning process beginning in predesign have been more recent. In one German national research program on energy optimization in buildings (ENOB), more than twenty demonstration buildings surpassed national energy consumption standards by $50 \%$ without incurring additional building costs. The program has been extended and now supports the design process, commissioning, and monitoring of the first two years of operation. ENOB also supports several projects focusing on improved commissioning and operation of innovative buildings. Energy agencies and utilities support energy efficiency through contracting and public private partnerships. Two other projects, ModBen and Building EQ, deal with performance evaluation of existing buildings.

The Netherlands: In the Netherlands, practitioners agree on the importance of building commissioning. However, it is currently only implemented in the installation and formal 
handover of selected buildings. A pilot project on functional performance tests conducted in forty buildings identified that $70 \%$ of the systems tested were malfunctioning, leading to increased energy use and reduced comfort. To improve system operation, large-building owners are investigating performance contracting for operations and maintenance, based on well-defined criteria. The commissioning process plays an important role. The Netherlands Organization for Applied Scientific Research is involved in the development of national standards concerning the energy performance of new buildings to promote the implementation of the whole commissioning process.

Norway: Building commissioning is not an established practice in Norway. A draft national commissioning guideline was developed in 2007 to promote the life-long commissioning of building HVAC systems. The guideline is currently under review and several large governmental and private building owners are involved in the effort to verify, document and implement suitable tools to provide continuous control of energy and indoor environment during the life of the building.

United Kingdom: The UK developed the earliest commissioning codes and provided the basis for similar work in many other countries. CIBSE published the first commissioning code on airdistribution systems in 1960 and subsequently released codes for other types of equipment. The emphasis of the commissioning codes was originally post-construction commissioning. Bordass (2008) reports that independent commissioning engineers were usually appointed as part of the design and build team in the late 1970's and early 1980's. However, as markets became more competitive, in the late 1980's and 1990's, commissioning was less commonly sold as a separate service and eventually became a subcontractor role, which had a negative impact on quality due to cost-cutting pressures. Today, initial commissioning has become routine for large projects and quality has once again improved but there are still major challenges in that the commissioning period is often squeezed when other delays impact the delivery date.

The current set of CIBSE commissioning codes includes: air distribution systems, boilers, automatic controls, lighting, management (Code $\mathrm{M}$ ), refrigeration, and water distribution systems. Code $\mathrm{M}$ shows an important change in the approach to the initial commissioning process by stating that the commissioning manager should be appointed early in the design phase in order for the system to be designed as commissionable.

Other organizations have also been directly involved in improving the commissioning industry. The Building Services Research and Information Association (BSRIA), a non-profit consulting design, construction, and operations organization is leading the "Soft landings" development with support from the Usable Buildings Trust, a non-profit organization dedicated to improving building performance through the better use of feedback. The Soft landings procedure aims to reduce the loss of information by extending the service of the design and building (and commissioning) team to facilitate fine-tuning and debugging at building handover in order to achieve a closer match between design targets and building operation, and to allow individuals to learn from the experience (BSRIA 2008). The Commissioning Specialists Association (CSA) is focused on career development, including training and certification of individuals.

Although retrocommissioning is not widespread, there is expected to be a major increase in its implementation as demand for improved energy and carbon performance increases, driven by new requirements of the EPBD, occupants, and building owners. 


\section{North America}

In North America, the concept of building commissioning began with the Code of Practice for Commissioning Mechanical Systems in Buildings that was developed in 1986 by the Standing Committee of Consulting Engineers and Mechanical Contractors of British Columbia. Today there are several, industry-recognized guidelines on the commissioning process: ASHRAE Guideline 1-1989 The HVAC Commissioning Process (revised in 1996), and ASHRAE Guideline 0-2005, The Commissioning Process. Although building systems commissioning is established practice in both Canada and the USA, the process is not widespread. Many of the existing resources are focused on conventional HVAC systems and there is need for information on other types of systems, particularly due to increased interest in non-conventional, low energy systems.

In Canada and the USA, awareness has increased through professional organizations, certification programs (e.g., LEED), large-owner mandates, and energy-efficiency initiatives. However, market barriers are significant. There is a need for greater awareness of the benefits and cost of commissioning to increase demand, and a need for more training and certification of commissioning providers to increase the supply. At present, building owners lack the access to experience and lessons learned in easily accessible, creditable and persuasive formats that would facilitate their investment decisions. Furthermore, tools and standardization are needed to reduce the cost of commissioning and improve the cost-benefit ratio for greater uptake. This includes automated tools, data on cost-benefits, and clear specifications for key building performance metrics, monitoring methods, and energy calculation methods.

Details of national initiatives are described below. 
Canada: Existing building commissioning in Canada is at the early stage of its development. While the demand for commissioning services remains stagnant, there are encouraging signs of activity transformation favorable to the creation of a better structured and more efficient market place. As more and more building owners and managers strive for energy conservation and building sustainability, their first step consists to improve their building operation efficiency. With the increase of energy prices, low cost technology availability and their practical advantages have strengthened the demand for energy-saving HVAC controls.

In order to support institutional and commercial businesses in this shifting market, the Ministry of Natural Resources Canada and its energy science and technology organization, CanmetENERGY, provides knowledge, services and tools for recommissioning, commissioning and ongoing commissioning projects. They offer to building engineers, technicians, owners, managers and other similar stakeholders a suite of capacity-building and decision-making tools, including guides, training material, awareness seminars, pre-screening and benchmarking tools and case studies. CanmetENERGY developed an application software tool ( $\left.\underline{\mathrm{DABO}^{\mathrm{TM}}}\right)$ to continuously monitor, detect and diagnose the operation inconsistencies and poor performances of a building's electromechanical systems.

Furthermore, the Demand Side Management Working Group (DSMWG) created by Natural Resources Canada collaborates with utilities, public works, green building associations and standard organizations on energy management to accelerate the training and certification of commissioning providers and to raise stakeholders' awareness on the benefits of commissioning work. The persistence of energy savings has also attracted the interest of DSMWG and action has been undertaken to implement a new Energy Management Information System (EMIS) component to the recommissioning process.

It is also worth mentioning that the Canadian Standard Association is preparing a new standard on commissioning that should come into effect in 2011.

USA: Rising energy costs and a shift in public policy that emphasizes the need for energy independence are driving energy conservation. In the absence of national commissioning requirements, individual state codes and institutional mandates have proven to be strong market drivers, though enforcement mechanisms have been problematic.

The buildings industry is working to address market barriers and improve the quality of its services. Non-profit organizations, including ASHRAE, Portland Energy Conservation, Inc. (PECI), the California Commissioning Collaborative and the Building Commissioning Association (BCA), provide access to industry resources for both providers and building owners, including:

A library of published papers and commissioning guides for retro-, initial, and on-going commissioning; tools: design guides, operations and maintenance best practices, case studies database; Sample documents: commissioning plans, specifications, functional tests, checklists; and training and certification programs, career and provider directories.

In recent years, market indicators show growth in the number of firms offering commissioning services. In 2008, 267 commissioning provider firms and 665 members registered with the BCA. There has also been a dramatic increase in commissioning certification and training provided by 
professional organizations, which indicate a demand by engineering professionals for more knowledge.

Utilities and government agencies have also invested resources on research and technology demonstration activities in an effort to stimulate the market for commissioning. More investment is needed to significantly improve the energy efficiency of the existing building stock, to meet the low energy targets for new construction, and to address the projected shortage of skilled and certified providers.

\subsection{Synthesized overview}

Commissioning is a promising quality assurance process and is gaining acceptance internationally as a means to improve building performance. The concept of commissioning originated in the UK in the 1960's and developed in Hong Kong and Canada in the 1980's. The process has been refined in individual countries and researchers are working with the building industry to merge the commissioning process with existing best practices to develop a more complete and streamlined approach to ensure that buildings operate as intended.

Within the building industry, the need for improved energy efficiency and quality assurance has long been evident, but shortsighted investment criteria and decisions present a major barrier. In recent years, rising energy consumption in buildings and greater awareness of their energy impact has prompted both national and international concerns regarding energy security and environmental security. Furthermore, much of the information on potential energy savings or cost savings through commissioning is anecdotal. There is an immediate need for research to establish standard methodologies to document actual costs and benefits.

International programs provide the basis for technology transfer and policy adoption. In the area of commissioning, this includes the IEA ECBCS Annex 40 and Annex 47 research projects, the international dissemination of commissioning information lead by national commissioning nonprofit organizations, and international commissioning projects. As a result of these interactions, individual countries have begun to adopt strategies to improve the performance of their existing building stock and improve the delivery process for new buildings.

Early investors in the commissioning process have attempted a number of different development paths including national research programs, industry guidelines, government mandates, training programs, demonstration projects, international collaborations, and the creation of non-profit organizations to gather resources and disseminate information. One of the most promising of these is the establishment of commissioning demonstration projects with detailed information about the associated costs and benefits of the process. The need for quantitative and qualitative information (beyond anecdotal reports) is universal. Demonstration projects can provide a foothold for the industry and justify the large owner mandates, national mandates, and additional measures that are needed to scale up the adoption of commissioning as standard practice.

The dissemination of information and education is also a critical component in establishing the commissioning process. Non-profit organizations including the BSCA, CIBSE, HCBCxC, and PECI have each played a key role in fostering interest in commissioning research and commissioning projects and exchanging information, first on national levels, and increasingly at international levels. 
Although the goals of reducing energy consumption and green house gases are gaining political support, investment still lags behind. There is a disparity between those who must invest in the development of commissioning technologies and those who would benefit. Because adoption has been slow, public and private partnerships are needed to grow both the supply side and the demand side of the commissioning market. On the supply side, there is a need for greater standardization of products and services. There is a dramatic shortage of skilled providers and a lack of resources to enable the industry to improve the building delivery process. On the demand side, resources are needed to make the business case for the long-term benefits of their investment. Owners lack the resources, such as contracting documents, and market information that is needed to facilitate the procurement of commissioning services. Harmonization is needed to assure that the process adequately spans the building lifecycle and to ensure that the benefits obtained in individual projects can be scaled up to meet national needs. Continued support for the development of the commissioning market is needed for a global increase in building performance. 


\section{$7 \quad$ References and Commissioning Guides}

\section{References}

Energy Design Resources, 1998, 'Design Brief Buildings Commissioning’

Grondzik, W., 2009, 'Principles of Building Commissioning', Wiley, ISBN: 978-0-470-11297-7

IEA ECBCS ANNEX 40, 2004, 'Commissioning Tools Final Report Annex 40'

Lawrence Berkeley National Laboratory, 20046, 'The Cost Effectiveness of

Commercial-Build ings $\mathrm{C}$ om $\mathrm{m}$ ission ing' .

Public work and government Services Canada, 2003, Commissioning Manual (CP.1-CP13)

\section{Commissioning Guides}

ASHRAE Guideline 1-1996: The HVAC Commissioning Process, ASHRAE, 2006, http://www. ashrae.org/

ASHRAE Guideline 0-2005: The commissioning process, ASHRAE, 2005, http://www. ashrae.org/

California Commissioning Guide: New Building, California commissioning collaborative, 2006, http://www.cacx.org/resources/documents/CA_Commissioning_Guide_New.pdf

Commissioning Guide for New Buildings, Natural Resources Canada, 2010, www.canmetenergy.nrcan.gc.ca/cx guide.html

Recommissioning (RCx) Guide for Building Owners and Managers, Natural Resources Canada, 2009, http://canmetenergy-canmetenergie. nrcan-

mcan.gc.ca/eng/buildings_communities/buildings/recommissioning/publications/2008167.html

Building Commissioning The Key to Quality Assurance, Rebuild America Guide Series, US Department Of Energy, 2001, http://www.peci.org/library/PECI_BldgCXQA1_0500.pdf 


\section{$8 \quad$ Annex 47 Participants}

\begin{tabular}{|c|c|c|}
\hline Name & Country & Affiliation \\
\hline Alexis Versele & Belgium & KaHo St-Lieven \\
\hline Hilde Breesch & Belgium & KaHo St-Lieven \\
\hline Stephane Bertagnolio & Belgium & University of Liege \\
\hline Daniel Choiniere & Canada & Natural Resources Canada \\
\hline Zhongxiian Gu & China & TNO Beijing \\
\hline Yongning Zhang & China & Tsinghua University \\
\hline Karel Kabele & Czech Republic & Czech Technical University \\
\hline Pavla Dvorakova & Czech Republic & Czech Technical University \\
\hline Michal Kabrhel & Czech Republic & Czech Technical University \\
\hline Mika Violle & Finland & Helsinki university \\
\hline Jorma Pietilainen & Finland & VTT \\
\hline Hannu Keranen & Finland & Helsinki university of Tech. \\
\hline Lari Eskola & Finland & HUT \\
\hline Satu Paiho & Finland & VTT \\
\hline Hossein Vaezi-Nejad & France & Dalkia \\
\hline Oliver Baumann & Germany & Ebert \& Baumann Consulting Eng. \\
\hline Steffen Plesser & Germany & IGS \\
\hline Christian Neumann & Germany & ISE \\
\hline Dirk Jacob & Germany & ISE \\
\hline Anatoli Hein & Germany & IGS \\
\hline Michele Liziero & Germany/Italy & $\begin{array}{l}\text { Politecnico di Milano, Guest Scientist at } \\
\text { Fraunhofer ISE }\end{array}$ \\
\hline Jochen Schaefer & Germany & Ebert \& Baumann Consulting Eng \\
\hline Shengwei Wang & HK/China & Hong Kong Polytechnic University \\
\hline Xinhua Xu & HK/China & Hong Kong Polytechnic University \\
\hline Zhenjun Ma & HK/China & Hong Kong Polytechnic University \\
\hline Zhou Cxiang & HK/China & Hong Kong Polytechnic University \\
\hline Xiao Fu Linda & HK/China & Hong Kong Polytechnic University \\
\hline $\mathrm{Na}$ Zhu & Honk kong & Hong Kong Polytechnic University \\
\hline Zoltan Magyar & Hungary & University of Pecs \\
\hline Csaba Fodor & Hungary & University of Pecs \\
\hline Harunori Yoshida & Japan & Kyoto University \\
\hline Motoi Yamaha & Japan & Chubu University \\
\hline Mingjie Zheng & Japan & Sanyo Air Conditioning \\
\hline
\end{tabular}




\begin{tabular}{|c|c|c|}
\hline Yasunori Akashi & Japan & Kyushu University \\
\hline Hiroo Sakai & Japan & Hitachi Plant Technologies \\
\hline Katuhiro Kamitani & Japan & Tonets Corporation \\
\hline Ryota Kuzuki & Japan & Tokyo Gas Co \\
\hline Katsuhiko Shibata & Japan & Takasago Thermal Eng. Co \\
\hline Fulin Wang & Japan & Kyoto University \\
\hline Masato Miyata & Japan & Kyoto University (student) \\
\hline Hirotake Shingu & Japan & Kyoto University (student) \\
\hline Hiromasa Yamaguchi & Japan & Kansai Electric Power Co \\
\hline Ryusi Yanagihara & Japan & Tokyo Electric Power Co \\
\hline Hideki Yuzawa & Japan & Nikken Sekkei Research Institute \\
\hline Takao Odajima & Japan & Takenaka Corp. \\
\hline hirobumi ueda & Japan & Osaka Gas CO., Ltd \\
\hline Masahiro Shinozaki & Japan & Kyushu Electric Power Co. \\
\hline Katsuhiro Kamitani & Japan & Tonets \\
\hline Mingjie zheng & Japan & SANKO AIR CONDITIONING CO.,LTD \\
\hline Katsuhiko Shibata & Japan & Takasago Thermal Engineering Co.Ltd \\
\hline Vojislav Novakovic & Norway & NTNU \\
\hline Natasa Djuric & Norway & NTNU \\
\hline Marko Masic & Norway & NTNU \\
\hline Vojislav Novakovic & Norway & NTNU \\
\hline Henk Peitsman & the Netherlands & TNO \\
\hline Luc Soethout & the Netherlands & TNO \\
\hline Ipek Gursel & the Netherlands & Delft University \\
\hline Natascha Milesi Ferretti & USA & $\begin{array}{l}\text { National Institute of Standards \& } \\
\text { Technology }\end{array}$ \\
\hline David Claridge & USA & Texas A\&M University \\
\hline Hannah Friedman & USA & Portland Energy Conservation Inc. \\
\hline Omer Akin & USA & Carnegie Mellon University \\
\hline Ashish Singhal & USA & Johnson Controls \\
\hline Tudy Haasl & USA & Portland Energy Conservation Inc \\
\hline Phil Haves & USA & Lawrence Berkley National Laboratory \\
\hline
\end{tabular}

